\title{
The value of preoperative urodynamics according to gynecologists and urologists with special interest in stress urinary incontinence
}

\author{
Sanne A. L. van Leijsen • Kirsten B. Kluivers • \\ Ben Willem J. Mol • Mark E. Vierhout • \\ John P. F. A. Heesakkers
}

Received: 15 March 2011 / Accepted: 30 August 2011 /Published online: 17 September 2011

(C) The Author(s) 2011. This article is published with open access at Springerlink.com

\begin{abstract}
Introduction and hypothesis The aim of this study is to assess variations in practice in the use of preoperative urodynamics in women with stress urinary incontinence (SUI).

Methods We performed an E-survey among all Dutch gynecologists and urologists who have SUI as focus in daily practice. The questions concerned the common policy and preferred policy. Descriptive statistics were used.

Results Of the 260 targeted specialists, 163 (63\%) responded. We found that $37 \%$ of the respondents performed standard preoperative urodynamics; in the preferred practice, this would reduce to only $18 \%$. Eighty percent indicated they would operate a patient with a positive stress test without urodynamic SUI, whereas $21 \%$ would do this also in case the clinical stress test was negative. Only $9 \%$ of the respondents indicated they adapted the choice of the type of sling based on urethral pressure profilometry parameters.
\end{abstract}

Electronic supplementary material The online version of this article (doi:10.1007/s00192-011-1565-2) contains supplementary material, which is available to authorized users.

S. A. L. van Leijsen $(\bowtie) \cdot$ K. B. Kluivers $\cdot$ M. E. Vierhout Department of Obstetrics \& Gynecology, Radboud University Nijmegen Medical Centre,

Postbox 9101, 6500 HB Nijmegen, the Netherlands

e-mail: s.vanleijsen@obgyn.umcn.nl

B. W. J. Mol

Department of Obstetrics \& Gynecology,

Academic Medical Centre,

Amsterdam, the Netherlands

J. P. F. A. Heesakkers

Department of Urology,

Radboud University Nijmegen Medical Centre,

Nijmegen, the Netherlands
Conclusions Urodynamics are not routinely performed, and outcomes hardly influence the choice of treatment.

Keywords Urodynamics · Stress urinary incontinence · Surgery $\cdot$ Practice variation
Abbreviations
SUI Stress urinary incontinence
DO Detrusor overactivity
TOT Transobturator tape
TVT Tension-free vaginal tape
OAB Overactive bladder
ISD Intrinsic sphincter deficiency
UPP Urethral pressure profile
VLPP Valsalva leak point pressure

\section{Introduction}

Stress urinary incontinence (SUI) is a frequently occurring problem. The Health Council of the Netherlands estimated that yearly 64,000 women consult their general practitioner because of urinary incontinence [1]. When conservative treatment fails, patients can opt for surgical therapy. The most common procedure for SUI is the midurethral sling procedure. These slings have an average success rate of $90 \%$ [2]. The introduction of these minimal invasive techniques for SUI therapy has led to an enormous increase in the number of operations in the Netherlands [3].

At present, there is an ongoing discussion among gynecologists and urologists regarding the need for urodynamics in the preoperative workup in women with (predominant) SUI. Urodynamics are an extension of signs and symptoms in an unphysiological setting. The informa- 
tion gained from urodynamic investigation may confirm or alter the clinical diagnosis or may influence the choice of intervention. When performing urodynamics, the assumption is that the urodynamic setting is capable of making a distinction between several pathophysiological mechanisms causing the same micturition symptoms. However, the urodynamic investigations that differentiate between several types of urinary incontinence and specify for the type of treatment lack validation and predictive value in individual cases [4]. Moreover, since the introduction of easy to administer midurethral polypropylene slings, a simplified reasoning has found ground that states that every type of SUI is treated in the same way, and therefore, no urodynamic investigation would be needed.

The National Institute for Clinical Excellence recommends since 2006 that the use of multichannel cystometry is not routinely needed before surgery in women with a clearly defined clinical diagnosis of pure SUI [5]. The test is recommended for women with a clinical suspicion of detrusor overactivity (DO), symptoms suggestive of voiding dysfunction, or in those with previous surgery for SUI or anterior compartment prolapse. In the Netherlands, the guidelines still advise to perform urodynamics in all patients prior to surgery to confirm the diagnosis of SUI and to detect factors which can influence the effectiveness of surgery and the probability of complications [6-8].

The implementation of these guidelines in clinical practice seems to be limited [9] and probably decreasing. During the set up of a randomized trial, we found that presently there is no uniform standard workup for women with SUI in clinical practice. There seems to be a wide variety in the diagnostic workup, ranging from women who are evaluated and treated in primary care settings without an extensive diagnostic evaluation till women who are directly referred to undergo urodynamics even before seeing the specialist. The objective of this study was to determine the use of urodynamics in current practice and the opinion about the need to perform preoperative urodynamic investigation in patients with SUI according to gynecologists and urologists with special interest in SUI.

\section{Materials and methods}

The target populations of this survey were gynecologists and urologists who have SUI treatment as focus in daily practice. A specific mailing list of these specialists was not available. Therefore, the questionnaire was emailed to all gynecologists and urologists in the Netherlands who are member of the Dutch Society of Obstetrics and Gynecology or the Dutch Urological Association. The member records comprise of approximately $98 \%$ of the Dutch practitioners. The number of target specialists was estimated at 190 gynecologists and 70 urologists based on information of the professional organizations.

The link to the survey was provided in the email. The answers were web-based collected by a digital E-survey. Name and hospital were checked for duplicates. In case the survey was answered anonymously, internet protocol (IP) address and completion time were checked. A reminder was sent after 3 weeks in order to enlarge the response rate.

The survey included a short letter to explain the purpose of the survey. In total, the questionnaire contained 26 questions and can be obtained on request from the corresponding author. The questions concerned the common policy and the preferred policy. The preferred policy refers to the ideal workup according to the respondents, regardless of the common practice in their hospital. All questions focused on women with SUI after conservative treatment but without prior incontinence surgery and without advanced pelvic organ prolapse (beyond POPQ stage 2). Various discordant findings on urodynamics were proposed, and respondents were asked what effect on their choice for treatment these findings would have. Multiple choice questions with the possibility to make a comment were designed to encourage complete answers. General questions regarding the number of anti-incontinence surgery performed yearly in the affiliated hospital and by the respondent, the number of urodynamics performed yearly, and the frequency of assessment of urodynamic curves by the respondent were also included.

Data are presented as percentage and mean percentage. Data were analyzed by using Statistical Package for the Social Sciences version 16.0. We used descriptive statistics. A summary of the survey details according to the Checklist for Reporting Results of Internet E-Surveys guidelines is shown in the Appendix [10].

\section{Results}

The survey was conducted in January 2010. We received 253 responses, of which five duplicates based on name or IP address were removed. Residents and non-practitioners were excluded from assay. The analysis was confined to 103 gynecologists and 60 urologists who indicated to have SUI treatment as focus in daily practice. The response rate among the target specialists was $65 \%(163 / 260 ; 54 \%$ for gynecologists and $86 \%$ for urologists). The characteristics of the respondents are shown in Table 1 . From 80 out of the 94 hospitals $(85 \%)$ in the Netherlands, at least one response was received. All eight Dutch university medical centers were represented. Table 2 shows the performance of preoperative urodynamics in the actual and preferred workup. The factors which were considered as indications to perform urodynamic investigation are shown in Table 3 . 
Table 1 Characteristics of respondents

\begin{tabular}{|c|c|c|c|c|}
\hline & & Gynecologists, $N=103$ & Urologists, $N=60$ & Total, $N=163$ \\
\hline \multirow[t]{4}{*}{ Type of hospital } & Academic & $8(8 \%)$ & $8(13 \%)$ & $16(10 \%)$ \\
\hline & Teaching & $49(48 \%)$ & $32(53 \%)$ & $81(50 \%)$ \\
\hline & Non-teaching & $34(33 \%)$ & $18(30 \%)$ & $52(32 \%)$ \\
\hline & Unknown & $12(12 \%)$ & $2(3 \%)$ & $14(9 \%)$ \\
\hline \multirow[t]{4}{*}{ MUS yearly in own hospital } & $0-10$ & $6(6 \%)$ & $3(5 \%)$ & $9(5 \%)$ \\
\hline & $0-50$ & $58(56 \%)$ & $37(62 \%)$ & $95(58 \%)$ \\
\hline & $>50$ & $35(34 \%)$ & $20(33 \%)$ & $55(34 \%)$ \\
\hline & $?$ & $4(4 \%)$ & 0 & $4(2 \%)$ \\
\hline \multirow[t]{4}{*}{ Operations yearly by specialist } & $0-10$ & $20(19 \%)$ & $18(30 \%)$ & $38(23 \%)$ \\
\hline & $0-50$ & $76(74 \%)$ & $36(60 \%)$ & $112(69 \%)$ \\
\hline & $>50$ & $4(4 \%)$ & $3(5 \%)$ & $7(4 \%)$ \\
\hline & $?$ & $3(3 \%)$ & $3(5 \%)$ & $6(4 \%)$ \\
\hline \multirow[t]{5}{*}{ Urodynamics results interpreted by an investigator } & Always & $43(42 \%)$ & $27(45 \%)$ & $70(43 \%)$ \\
\hline & Often & $21(20 \%)$ & $7(12 \%)$ & $28(17 \%)$ \\
\hline & Sometimes & $12(12 \%)$ & $9(15 \%)$ & $21(13 \%)$ \\
\hline & Never & $20(19 \%)$ & $17(28 \%)$ & $37(23 \%)$ \\
\hline & $?$ & $7(7 \%)$ & 0 & $7(4 \%)$ \\
\hline \multirow[t]{4}{*}{ Able to read urodynamics } & Yes & $55(53 \%)$ & $55(92 \%)$ & $110(67 \%)$ \\
\hline & No & $42(41 \%)$ & $3(5 \%)$ & $45(28 \%)$ \\
\hline & $?$ & $6(6 \%)$ & $2(3 \%)$ & $8(5 \%)$ \\
\hline & & Mean (range) & & \\
\hline \multirow[t]{6}{*}{ Type of procedure } & Retropubic sling & $20 \%(0-100)$ & $22 \%(0-100)$ & $21 \%(0-100)$ \\
\hline & Transobturator sling & $69 \%(0-100)$ & $65 \%(0-100)$ & $70 \%(0-100)$ \\
\hline & Minisling & $4 \%(0-95)$ & $9 \%(0-100)$ & $6 \%(0-100)$ \\
\hline & Burch & $1 \%(0-15)$ & $3 \%(0-80)$ & $1 \%(0-80)$ \\
\hline & Bulk injections & $1 \%(0-20)$ & $1 \%(0-10)$ & $1 \%(0-20)$ \\
\hline & Other & $0 \%(0-2)$ & $1 \%(0-20)$ & $1 \%(0-20)$ \\
\hline
\end{tabular}

MUS midurethral sling, ? respondent answered "I don’t know"

In case SUI cannot be demonstrated on urodynamic investigation but the stress test is positive on clinical examination, 83 gynecologists (81\%) and 47 urologists (78\%) would operate on the patient. In case the SUI could not be demonstrated during physical examination nor at urodynamics, only 22 gynecologists (21\%) and 11 urologists $(18 \%)$ would operate.

A history of overactive bladder (OAB) with suspected DO, e.g., urgency symptoms or a micturition frequency of more than seven times a day, was the most common

Table 2 Actual and preferred policy concerning the performance of preoperative urodynamics in women with (predominant) stress incontinence, displayed as number and percentage of the respondents

\begin{tabular}{|c|c|c|c|c|c|c|c|c|}
\hline & & \multicolumn{3}{|l|}{ Specialist } & \multicolumn{4}{|c|}{ Hospital type } \\
\hline & & $\begin{array}{l}\text { Gynecologists } \\
N=103\end{array}$ & $\begin{array}{l}\text { Urologists } \\
N=60\end{array}$ & $\begin{array}{l}\text { Total } \\
N=163\end{array}$ & $\begin{array}{l}\text { Academic } \\
N=16\end{array}$ & $\begin{array}{l}\text { Teaching } \\
N=81\end{array}$ & $\begin{array}{l}\text { Non-teaching } \\
N=52\end{array}$ & $\begin{array}{l}\text { Unknown } \\
N=14\end{array}$ \\
\hline \multirow[t]{3}{*}{ Common policy } & Always & $34(33 \%)$ & $26(43 \%)$ & $60(37 \%)$ & $10(63 \%)$ & $31(38 \%)$ & $15(29 \%)$ & $4(29 \%)$ \\
\hline & Indication & $52(51 \%)$ & $26(43 \%)$ & $78(48 \%)$ & $5(31 \%)$ & $37(46 \%)$ & $27(52 \%)$ & $9(64 \%)$ \\
\hline & Never & $17(17 \%)$ & $8(13 \%)$ & $25(15 \%)$ & $1(6 \%)$ & $13(16 \%)$ & $5(19 \%)$ & $1(7 \%)$ \\
\hline \multirow[t]{4}{*}{ Preferred practice } & Always & $17(17 \%)$ & $12(20 \%)$ & $29(18 \%)$ & $4(25 \%)$ & $11(14 \%)$ & $9(17 \%)$ & $5(36 \%)$ \\
\hline & Indication & $66(64 \%)$ & $39(65 \%)$ & $104(64 \%)$ & $10(63 \%)$ & $55(68 \%)$ & $32(62 \%)$ & $8(57 \%)$ \\
\hline & Never & $19(18 \%)$ & $9(15 \%)$ & $28(17 \%)$ & $2(13 \%)$ & $14(17 \%)$ & $11(21 \%)$ & $1(7 \%)$ \\
\hline & Unknown & $1(1 \%)$ & & $3(1 \%)$ & & $1(1 \%)$ & & \\
\hline
\end{tabular}


Table 3 Indications to perform urodynamics in the preferred practice

\begin{tabular}{|c|c|c|c|c|c|c|c|c|}
\hline & & \multicolumn{3}{|l|}{ Specialist } & \multicolumn{4}{|c|}{ Hospital type } \\
\hline \multicolumn{2}{|c|}{ Indication to perform urodynamics } & $\begin{array}{l}\text { Gynecologists } \\
N=66\end{array}$ & $\begin{array}{l}\text { Urologists } \\
N=39\end{array}$ & $\begin{array}{l}\text { Total } \\
N=105\end{array}$ & $\begin{array}{l}\text { Academic } \\
N=10\end{array}$ & $\begin{array}{l}\text { Teaching } \\
N=55\end{array}$ & $\begin{array}{l}\text { Non-teaching } \\
N=32\end{array}$ & $\begin{array}{l}\text { Unknown } \\
N=8\end{array}$ \\
\hline \multirow[t]{3}{*}{ OAB complaints } & Urgency & $63(95 \%)$ & $30(77 \%)$ & $93(89 \%)$ & $9(90 \%)$ & $48(87 \%)$ & $30(94 \%)$ & $6(75 \%)$ \\
\hline & Frequency $^{\mathrm{a}}$ & $43(65 \%)$ & $20(51 \%)$ & $63(60 \%)$ & $8(80 \%)$ & $29(53 \%)$ & $22(69 \%)$ & $4(50 \%)$ \\
\hline & $\begin{array}{l}\text { Small maximum } \\
\text { volume }^{\mathrm{b}}\end{array}$ & $40(61 \%)$ & $21(54 \%)$ & $61(58 \%)$ & $6(60 \%)$ & $34(62 \%)$ & $18(56 \%)$ & $3(37 \%)$ \\
\hline \multirow{2}{*}{$\begin{array}{l}\text { Voiding } \\
\text { dysfunction }\end{array}$} & Residual sensation & $39(59 \%)$ & $13(33 \%)$ & $53(50 \%)$ & $4(40 \%)$ & $28(51 \%)$ & $17(53 \%)$ & $3(38 \%)$ \\
\hline & Poor flow & $36(55 \%)$ & $26(67 \%)$ & $62(59 \%)$ & $6(60 \%)$ & $34(62 \%)$ & $19(60 \%)$ & $3(38 \%)$ \\
\hline Hyposensitivity & $\begin{array}{l}\text { Large maximum } \\
\text { volume }^{\mathrm{b}}\end{array}$ & $14(21 \%)$ & $12(31 \%)$ & $26(25 \%)$ & $3(30 \%)$ & $13(24 \%)$ & $7(22 \%)$ & $3(38 \%)$ \\
\hline \multicolumn{2}{|l|}{$\begin{array}{r}\text { Stress test } \\
\text { negative }\end{array}$} & $29(44 \%)$ & $13(33 \%)$ & $42(40 \%)$ & $5(50 \%)$ & $25(46 \%)$ & $9(28 \%)$ & $3(38 \%)$ \\
\hline
\end{tabular}

Indicative findings of history taking, voiding diary or clinical examination, and the frequency were mentioned to form an indication to perform a urodynamic investigation. Data are expressed as number and percentage of the respondents who have indicated to perform urodynamics on indication in the preferred practice

$O A B$ overactive bladder

${ }^{a}$ More than seven times a day

${ }^{\mathrm{b}}$ On voiding diary

indication to perform preoperative urodynamics. DO on urodynamics was an important reason not to perform an operation. In case urodynamic investigation showed detrusor overactivity, 13 gynecologists $(13 \%)$ and 12 urologists $(20 \%)$ would perform surgery and only in case of complaints afterwards would start anticholinergics. Ninety gynecologists $(87 \%)$ and 48 urologists $(80 \%)$ would renounce or reconsider the operation for SUI and start a treatment aimed at controlling DO first.

Ninety-three respondents (57\%) indicated that a urethral pressure profile (UPP) is part of a standard urodynamic investigation. Only 15 respondents $(9 \%)$, however, would choose the type and technique of surgery based on UPP outcome, especially the maximum urethral closure pressure.

Only three respondents $(2 \%)$ mentioned to use the maximum urethral closure pressure when counseling on success rates. Sixty-eight respondents $(42 \%)$ indicated that a Valsalva leak point pressure (VLPP) is part of a standard urodynamic investigation. Fifty-two respondents (32\%) indicated that neither a UPP nor a VLPP is performed during urodynamics.

One hundred and seventeen respondents $(72 \%)$ indicated to use only one type of sling in more than $90 \%$ of all antiincontinence procedures; in $55 \%$ a transobturator tape (TOT), in $15 \%$ a retropubic sling, and in $2 \%$ a single incision sling is used in more than $90 \%$ of cases. Seventytwo respondents (44\%) indicated to use only one type of sling in all procedures.

The interpretation of the urodynamic investigation is in $43 \%$ always performed by the specialist that orders the investigation. Forty-two gynecologists $(41 \%)$ indicated to be unable to interpret the curves of an urodynamic investigation themselves, versus only two urologists (3\%).

\section{Discussion}

This is a report on practice variation and the perceived value of preoperative urodynamics according to gynecologists and urologists with special interest in SUI treatment in the Netherlands. Although urodynamics are widely used, it still needs to show evidence that performing urodynamics does improve the outcome of anti-incontinence procedures [11]. Despite this, guidelines recommend that women undergoing surgery for stress incontinence should have urodynamic investigations prior to treatment [6-8]. This study shows that existing guidelines are very poorly implemented. Only in one third of the respondents does the standard workup before SUI surgery comprises a urodynamic investigation, and in the preferred setting, this would be only one fifth. The majority prefers to perform urodynamics only when there is an indication during history taking, voiding diary, or clinical examination. The indications as well as the related consequences of urodynamic findings vary widely.

The respondents seem to attribute substantial relevance to the stress test during clinical examination. The cough stress test has a reported sensitivity of $0.85(0.78-0.91)$ and specificity of $0.83(0.74-0.90)$ for the diagnosis of urodynamic SUI in women compared with multichannel urodynamics [12]. A relation between the result of the stress test during clinical examination and clinical outcome 
is however not reported. One study showed higher, albeit not significant, overall success in women with a positive stress test during both clinical examination and urodynamic SUI, as compared to women with a positive stress test during clinical examination only [13].

The perceived value of the stress test during clinical examination illustrates that in clinical practice, urodynamics are mostly not used as confirmation of the diagnosis of an incompetent sphincter mechanism. The revealed information on the risk of failure and complications like de novo urgency or aggravation of urgency and urinary retention was considered more important. This management is in line with previous studies which have shown less successful treatment outcomes in patients with DO, voiding dysfunction, or intrinsic sphincter deficiency (ISD) [14-17].

However, when urodynamics are only performed in patients with symptoms or signs, many patients would be misdiagnosed. In patients without complaints of $\mathrm{OAB}$, in $20 \%$ detrusor overactivity was found [18]. The majority indicated to renounce a primarily surgical treatment when preoperative DO is found.

Although there is a lack of controlled studies available on whether urodynamics predict stress incontinence outcome, it is reported that the subjective cure rate of SUI after surgical treatment decreases in case of preoperative DO [9, $19,20]$. However, it has been shown as well that SUI and UUI can be cured in $50-85 \%$ of women with MUI after colposuspension and MUS [21-23]. Therefore, the preoperative diagnosis of DO could attribute to the counseling of patients about the perspectives of surgery, but it is a question whether it should influence the choice of treatment.

A recent meta-analysis of randomized controlled trials, as well as a randomized equivalence trial, on the effectiveness of the TOT compared to the retropubic tape in women with SUI revealed that classic TVT appeared to be followed by higher objective cure rates than the TOT but with no difference in subjective cure rates and at the cost of higher risks of operative complications, voiding dysfunction, and storage lower urinary tract symptoms [22, 24, 25]. For women with ISD (maximum urethral closure pressure less than $20 \mathrm{~cm} \mathrm{H}_{2} \mathrm{O}$ ), the retropubic tape appears to be a better option because it is more obstructive [24, 26-28]. After a longer period of follow-up, women with SUI and ISD are significantly less likely to require further SUI surgery with the retropubic tape than the TOT [29]. Therefore, the use of the UPP could attribute to the determination of the most effective type of sling in individuals. However, in Dutch practice, the choice of sling was rarely especially based on this measurement. Possibly, this is due to surgeon's experience and familiarity with only one type of sling procedures (transobturator or retropubic tapes) or to a poor understanding of the interpretation of the UPP. Two thirds of the respondents indicated to use one particular sling in more than $90 \%$ of procedures, and almost half of them use only one type of sling in all their patients.

This study shows that the expertise, especially of gynecologists, in the interpretation of urodynamic curves is poor. This is despite the fact that the final qualifications of the training to gynecologists contain the objective to be capable to interpret the results of urodynamics [30]. Our target population consisted of gynecologists with special interest in SUI; it is reasonable that they should have a good understanding of urodynamic theory and practice. In case the interpretation of urodynamic curves or written results is performed without complete understanding, the results will not be reliable and less valuable.

The limitations of the conclusions offered by this survey include the shortcomings of web surveys in general and the moderate response rate. However, bias was avoided by exclusion of residents and specialist not treating women for urinary incontinence in the analysis. Also, multiple entries from the same individual were avoided. All kinds of hospitals were represented (academic, teaching, and nonteaching hospitals). Therefore, the included responses are thought to be representative of the Dutch specialists treating SUI in daily practice.

The variety in the use of preoperative urodynamics indicates the necessity of conclusive evidence on patient groups in whom a preoperative urodynamic investigation is valuable. As suggested in previous reports, a randomized controlled trial in this specific patient group can show which patients would benefit from preoperative urodynamics $[11,31]$. This might lead to adaptation of guidelines and a more uniform workup. In case predictive information retrieved from urodynamics does, however, not lead to an adjustment of treatment strategy, a potential positive value of urodynamics would still be lost.

\section{Conclusion}

Guidelines on indications for urodynamics are not widely implemented, resulting in practice variation in the preoperative workup in women with (predominant) SUI. Urodynamics are not routinely performed as indicated, and the outcomes hardly influence the choice of treatment. The practice variability indicates the necessity of conclusive evidence on the patients in whom to perform preoperative urodynamic investigation, and a consequent modification and implementation of the guideline in order to create a more uniform workup.

Conflicts of interest MV is a member of the European OAB faculty of Astellas. This study was however entirely instigated by the responsible researchers. No commercial partner was involved in the study setup, study design, or data collection. The other authors have no conflicts of interest to declare. 
Open Access This article is distributed under the terms of the Creative Commons Attribution Noncommercial License which permits any noncommercial use, distribution, and reproduction in any medium, provided the original author(s) and source are credited.

\section{References}

1. Health Council of the Netherlands (2001) Urinary incontinence. Health Council of the Netherlands, The Hague, Publication no. 2001/12

2. Abrams P, Cardozo L, Khoury S, Wein A (2009) Incontinence, 4th edn. Health Publications Ltd., Plymouth

3. Vierhout ME (2005) Increase in number of operations for stress urinary incontinence. Ned Tijdschr Geneeskd 149(30):1704-1706

4. Chapple CR (2005) Primer: questionnaires versus urodynamics in the evaluation of lower urinary tract dysfunction - one, both or none? Nat Clin Pract Urol 2(11):555-564

5. NICE (2006) Urinary incontinence: the management of urinary incontinence in women. NICE, London

6. Groenendijk AG, Vervest HAM, van der Vaart $\mathrm{CH}$, van Geelen JM (2004) Richtlijn Urine-incontinentie (Guideline Urinary Incontinence). Ned Vereniging voor Obstetrie en Gynaecologie 2004 Sep

7. Venema PL, van Geelen JM, Kil PJM, et al. (2003) Richtlijn Stressincontinentie bij de vrouw (Guideline stress incontinence in women). Nederlandse Vereniging voor Urologie

8. Dutch College of General Practice (2009) Incontinence for urine

9. Duggan PM, Wilson PD, Norton P, Brown AD, Drutz HP, Herbison P (2003) Utilization of preoperative urodynamic investigations by gynecologists who frequently operate for female urinary incontinence. Int Urogynecol J Pelvic Floor Dysfunct 14 (4):282-287

10. Eysenbach G (2004) Improving the quality of Web surveys: the Checklist for Reporting Results of Internet E-Surveys (CHERRIES). J Med Internet Res 6(3):e34

11. Glazener CM, Lapitan MC (2002) Urodynamic investigations for management of urinary incontinence in adults. Cochrane Database Syst Rev 3:CD003195

12. Martin JL, Williams KS, Abrams KR et al (2006) Systematic review and evaluation of methods of assessing urinary incontinence. Health Technol Assess 10(6):1-132, iii-iv

13. Nager CW, FitzGerald M, Kraus SR et al (2008) Urodynamic measures do not predict stress continence outcomes after surgery for stress urinary incontinence in selected women. J Urol 179 (4): $1470-1474$

14. Colombo M, Zanetta G, Vitobello D, Milani R (1996) The Burch colposuspension for women with and without detrusor overactivity. Br J Obstet Gynaecol 103(3):255-260

15. Thompson PK, Duff DS, Thayer PS (2000) Stress incontinence in women under 50: does urodynamics improve surgical outcome? Int Urogynecol J Pelvic Floor Dysfunc 11(5):285-289

16. O'Connor RC, Nanigian DK, Lyon MB, Ellison LM, Bales GT, Stone AR (2006) Early outcomes of mid-urethral slings for female stress urinary incontinence stratified by valsalva leak point pressure. Neurourol Urodyn 25(7):685-688
17. Paick JS, Ku JH, Shin JW, Son H, Oh SJ, Kim SW (2004) Tension-free vaginal tape procedure for urinary incontinence with low Valsalva leak point pressure. J Urol 172(4 Pt 1):1370-1373

18. Digesu GA, Khullar V, Cardozo L, Salvatore S (2003) Overactive bladder symptoms: do we need urodynamics? Neurourol Urodyn 22(2):105-108

19. Houwert RM, Venema PL, Aquarius AE, Bruinse HW, Roovers JP, Vervest HA (2009) Risk factors for failure of retropubic and transobturator midurethral slings. Am J Obstet Gynecol 201 (2):202-208

20. Paick JS, Oh SJ, Kim SW, Ku JH (2008) Tension-free vaginal tape, suprapubic arc sling, and transobturator tape in the treatment of mixed urinary incontinence in women. Int Urogynecol J Pelvic Floor Dysfunct 19(1):123-129

21. Lai HH, Simon M, Boone TB (2006) The impact of detrusor overactivity on the management of stress urinary incontinence in women. Curr Urol Rep 7(5):354-362

22. Duckett JR, Tamilselvi A (2006) Effect of tension-free vaginal tape in women with a urodynamic diagnosis of idiopathic detrusor overactivity and stress incontinence. BJOG 113(1):30-33

23. Rezapour M, Ulmsten U (2001) Tension-free vaginal tape (TVT) in women with mixed urinary incontinence - a long-term followup. Int Urogynecol J Pelvic Floor Dysfunct 12(Suppl 2):S15-S18

24. Novara G, Artibani W, Barber MD, Chapple CR, Costantini E, Ficarra $\mathrm{V}$ et al (2010) Updated systematic review and metaanalysis of the comparative data on colposuspensions, pubovaginal slings, and midurethral tapes in the surgical treatment of female stress urinary incontinence. Eur Urol 58(2):218-238

25. Richter HE, Albo ME, Zyczynski HM, Kenton K, Norton PA, Sirls LT et al (2010) Retropubic versus transobturator midurethral slings for stress incontinence. N Engl J Med 362(22):2066-2076

26. Long C-Y, Hsu C-S, Wu M-P, Liu C-M, Wang T-N, Tsai E-M (2009) Comparison of tension-free vaginal tape and transobturator tape procedure for the treatment of stress urinary incontinence. Curr Opin Obstet Gynecol 4:342-347

27. Schierlitz L, Dwyer PL, Rosamilia A, Lim YN (2009) Effectiveness of tension-free vaginal tape compared with transobturator tape in women with stress urinary incontinence and intrinsic sphincter deficiency: a randomized controlled trial. Obstet Gynecol 113(6):1368-1369

28. Gungorduk K, Celebi I, Ark C, Celikkol O, Yildirim G (2009) Which type of mid-urethral sling procedure should be chosen for treatment of stress urinary incontinance with intrinsic sphincter deficiency? Tension-free vaginal tape or transobturator tape. Acta Obstet Gynecol Scand 88(8):920-926

29. Schierlitz L, Dwyer P, Rosamilia A, Murray C, Thomas E, Fitzgerald E, et al. (2010) A randomized controlled study to compare tension free vaginal tape (TVT) and monarc transobturator tape in the treatment of women with urodynamic stress incontinence (USI) and intrinsic sphincter deficiency (ISD): the three year follow-up. ICS/IUGA meeting, Toronto

30. Dutch Society of Obstetrics and Gynaecology (2000) Nota Eindtermen Verloskunde en Gynaecologie (1.0). 1-1-2000

31. Palma P, Herrmann V (2007) Urodynamics and stress urinary incontinence: the dark side of a gold standard. Int Urogynecol J Pelvic Floor Dysfunct 18(12):1385-1386 